\section{BRAZIULIAN JOURNAL}

OF MEDICAL AND BIOLOGICAL RESH ARCH

www.bjournal.com.br
ISSN 0100-879X

Volume 42 (12) 1119-1247 December 2009

BIOMEDICAL SCIENCES

AND

CLINICAL INVESTIGATION

Braz J Med Biol Res, December 2009, Volume 42(12) 1179-1184

Pharmacogenetic polymorphisms in Brazilian-born, first-generation Japanese descendants

J.A. Perini, D.D. Vargens, I.S.C. Santana, E.H. Moriguchi, A.K.C. Ribeiro-dos-Santos, M. Tsutsumi and G. Suarez-Kurtz

The Brazilian Journal of Medical and Biological Research is partially financed by
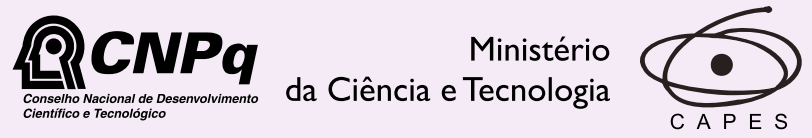

Ministério da Educação

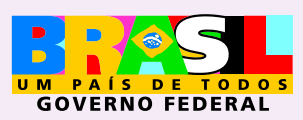

Institutional S ponsors 


\title{
Pharmacogenetic polymorphisms in Brazilian-born, first-generation Japanese descendants
}

\author{
J.A. Perini ${ }^{1}$, D.D. Vargens ${ }^{1}$, I.S.C. Santana ${ }^{1}$, E.H. Moriguchi², \\ A.K.C. Ribeiro-dos-Santos ${ }^{3}$, M. Tsutsumi ${ }^{3}$ and G. Suarez-Kurtz ${ }^{1}$ \\ ${ }^{1}$ Divisão de Farmacologia, Instituto Nacional de Câncer, Rio de Janeiro, RJ, Brasil \\ 2Programa de Pós-Graduação em Ciências da Saúde, Cardiologia e Ciências Cardiovasculares, \\ Faculdade de Medicina, Universidade Federal do Rio Grande do Sul, Porto Alegre, RS, Brasil \\ ${ }^{3}$ Laboratório de Genética Humana e Médica, Instituto de Ciências Biológicas, \\ Universidade Federal do Pará, Belém, PA, Brasil
}

\begin{abstract}
Brazil hosts the largest Japanese community outside Japan, estimated at 1.5 million individuals, one third of whom are firstgeneration, Brazilian-born with native Japanese parents. This large community provides a unique opportunity for comparative studies of the distribution of pharmacogenetic polymorphisms in native Japanese versus their Brazilian-born descendants. Functional polymorphisms in genes that modulate drug disposition (CYP2C9, CYP2C19 and GSTM3) or response (VKORC1) and that differ significantly in frequency in native Japanese versus Brazilians with no Japanese ancestry were selected for the present study. Healthy subjects (200 native Japanese and 126 first-generation Japanese descendants) living in agricultural colonies were enrolled. Individual DNA was genotyped using RFLP $\left(G S T M 3^{*} A / B\right)$ or TaqMan Detection System assays (CYP2C9*2 and *3; CYP2C19*2 and *3; VKORC1 3673G>A, 5808T>G, 6853G>C, and 9041G>A). No difference was detected in the frequency of these pharmacogenetic polymorphisms between native Japanese and first-generation Japanese descendants. In contrast, significant differences in the frequency of each polymorphism were observed between native or first-generation Japanese and Brazilians with no Japanese ancestry. The VKORC1 3673G>A, 6853G>C and 9041G>A single nucleotide polymorphisms were in linkage disequilibrium in both native and first-generation Japanese living in Brazil. The striking similarity in the frequency of clinically relevant pharmacogenetic polymorphisms between Brazilian-born Japanese descendants and native Japanese suggests that the former may be recruited for clinical trials designed to generate bridging data for the Japanese population in the context of the International Conference on Harmonization.
\end{abstract}

Key words: Japanese; Brazil; CYP2C9; CYP2C19; GSTM3; VKORC1

\section{Introduction}

Myrand et al. (1) reported that native Japanese and Japanese descendants born and living outside Japan display strikingly similar drug metabolic profiles for major cytochrome P450 (CYP) enzymes. It has been suggested that pharmacokinetic data from Japanese recruited outside Japan may be used to bridge foreign clinical data between Caucasians and Asians, in the context of the International Conference on Harmonization (ICH). The $\mathrm{ICH}$ is a tripartite body composed of the regulatory authorities and the industry associations of the European Community, Japan and the United States with observers from the World Health Organization, Health Canada and European Free Trade Area countries, charged with developing guidelines to harmonize global drug development and thus facilitate availability of new medicines efficiently. Brazil hosts the largest Japanese community outside Japan, estimated to be 1.5 million individuals, $4 \%$ of whom are native Japanese (2) and ca. one third are first-generation, Brazilian-born individuals with native Japanese parents (3). This large community provides a unique opportunity for comparative studies of the distribution of pharmacogenetic polymorphisms among native Japanese, their Brazilian-born descendants and Brazilians with no Japanese ancestry. For the present study, we selected functional polymorphisms in genes that modulate drug disposition (CYP2C9, CYP2C19 and GSTM3) or response to drugs (VKORC1) and that differ significantly in their frequencies in native Japanese versus Brazilians with no Japanese ancestry (4-8). Recruitment of Brazilian-born

Correspondence: G. Suarez-Kurtz, Divisão de Farmacologia, Instituto Nacional de Câncer, Rua André Cavalcanti, 37, $21230-050$ Rio de Janeiro, RJ, Brasil. Fax: +55-21-3233-1340. E-mail: kurtz@inca.gov.br

Received June 24, 2009. Accepted October 13, 2009. Available online October 30, 2009. Published December 4, 2009. 
individuals with Japanese ancestry in relatively isolated agricultural colonies minimized the impact of genetic admixture on the frequency of the chosen polymorphisms, and also increased the likelihood of providing pharmacogenetic data to support the proposal that Japanese descendants living outside Japan may be enrolled in clinical trials designed to generate bridging data for the Japanese population, in the context of the ICH (1).

\section{Material and Methods}

\section{Study population}

The study enrolled 200 native Japanese (median age 64 years, range 32-88) and 126 Brazilian-born, first-generation Japanese descendants (42 years, range 25-74), all living in agricultural colonies in Brazil's South (Ivoti,

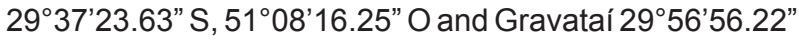
S, $\left.50^{\circ} 59^{\prime} 29.62^{\prime \prime} \mathrm{O}\right)$ and North regions (Tomé-Açu, $\left.2^{\circ} 2^{\prime} 59.92^{\prime \prime} \mathrm{S}, 48^{\circ} 07^{\prime} 10.54^{\prime \prime} \mathrm{O}\right)$. The study was approved by the Ethics Committee of Pontifícia Universidade Católica do Rio Grande do Sul, and each subject provided written informed consent and information regarding Japanese ancestry. Data from Brazilians living in Rio de Janeiro, with no Japanese ancestry, previously genotyped in our laboratory for polymorphisms in CYP2C9 (6), CYP2C19
(Suarez-Kurtz G, unpublished data), GSTM3 (7), and VKORC1 (8) were used for comparison.

\section{Genotyping}

A single blood sample $(3 \mathrm{~mL})$ was drawn from each subject and DNA was extracted using the GFX ${ }^{\mathrm{TM}}$ GenoBlood DNA Purification Kit (Amersham Biosciences, USA). Validated TaqMan ${ }^{\circledR}$ assays (Applied Biosystems, USA) were used to discriminate the VKORC1 3673G $>$ A (rs9923231), VKORC1 5808T>G (rs2884737), VKORC1 6853G>C (rs8050894), VKORC1 9041G>A (rs7294), CYP2C9*2 (rs1799853), CYP2C9*3 (rs1057910), CYP2C19*2 (rs4244285), and CYP2C19*3 (rs4986893) alleles. Polymerase chain reaction amplification for all single nucleotide polymorphisms was performed in $10-\mu \mathrm{L}$ reactions with $30 \mathrm{ng}$ template DNA, 1X Taqman Universal Master Mix (Applied Biosystems), 1X each primer and probe assay, and $\mathrm{H}_{2} \mathrm{O}$ qsp. Thermal cycling was initiated with a first denaturation step of $10 \mathrm{~min}$ at $95^{\circ} \mathrm{C}$, followed by 40 cycles of denaturation at $92^{\circ} \mathrm{C}$ for $15 \mathrm{~s}$ and annealing at $60^{\circ} \mathrm{C}$ for $1 \mathrm{~min}$. The allele detection process was performed for $1 \mathrm{~min}$ at $60^{\circ} \mathrm{C}$ on a Fast 7500 Real-Time System (Applied Biosystems) to determine the allelic discrimination. The GSTM3*A/B polymorphism, a 3-bp insertion/ deletion in intron 6 (rs1799735), was genotyped by RFLP

Table 1. Allele frequencies and genotype distribution of CYP2C9 and CYP2C19 polymorphisms.

\begin{tabular}{|c|c|c|c|c|c|}
\hline \multicolumn{2}{|c|}{ Single nucleotide polymorphisms } & \multirow{2}{*}{$\frac{\text { Native Japanese }^{a}}{84(94.4 \%)}$} & \multirow{2}{*}{$\frac{\text { First-generation }^{a}}{63(98.4 \%)}$} & \multirow{2}{*}{$\frac{\text { Non-Japanese Brazilian }}{\text { b }}$} & \multirow[t]{2}{*}{$\mathrm{P}$} \\
\hline CYP2C9 & $* 1 / * 1$ & & & & \\
\hline & $* 1 / * 2$ & 0 & 0 & $48(14.5 \%)$ & \multirow{5}{*}{$<0.0001$} \\
\hline & $* 1 / * 3$ & $5(5.6 \%)$ & $1(1.6 \%)$ & $36(10.9 \%)$ & \\
\hline & ${ }^{*} 2 /{ }^{*} 2$ & 0 & 0 & $3(0.9 \%)$ & \\
\hline & ${ }^{*} 2 /{ }^{*} 3$ & 0 & 0 & $3(0.9 \%)$ & \\
\hline & $* 3 / * 3$ & 0 & 0 & $2(0.6 \%)$ & \\
\hline & *2 & 0 & 0 & $57(8.6 \%)$ & \multirow{2}{*}{$<0.0001$} \\
\hline & *3 & $5(2.8 \%)$ & $1(0.8 \%)$ & $43(6.5 \%)$ & \\
\hline \multirow[t]{8}{*}{ CYP2C19 } & $* 1 / * 1$ & $27(33.8 \%)$ & $24(40.7 \%)$ & $195(74.7 \%)$ & \multirow{6}{*}{$<0.0001$} \\
\hline & $* 1 / * 2$ & $31(38.8 \%)$ & $15(25.4 \%)$ & $61(23.4 \%)$ & \\
\hline & $* 1 / * 3$ & $9(11.3 \%)$ & $7(11.9 \%)$ & $1(0.4 \%)$ & \\
\hline & ${ }^{*} 2 /{ }^{*} 2$ & $5(6.3 \%)$ & $5(8.5 \%)$ & $4(1.5 \%)$ & \\
\hline & ${ }^{*} 2 /{ }^{*} 3$ & $8(10.0 \%)$ & $7(11.9 \%)$ & 0 & \\
\hline & ${ }^{*} 3 /{ }^{*} 3$ & 0 & $1(1.7 \%)$ & 0 & \\
\hline & *2 & $49(30.6 \%)$ & $32(27.1 \%)$ & $69(13.2 \%)$ & \multirow{2}{*}{$<0.0001$} \\
\hline & *3 & $17(10.6 \%)$ & $16(13.6 \%)$ & $1(0.2 \%)$ & \\
\hline
\end{tabular}

Data are reported as number with percent in parentheses. alndividuals from Brazil's South region. bN $=331$ for CYP2C9 (Ref. 4) and $\mathrm{N}=261$ for CYP2C19 (Suarez-Kurtz G, unpublished data). Chi-square test or, when appropriate, Fisher exact test for comparisons of allele frequencies or genotype distribution across the three groups. 
as described previously (9) and CYP2C9, CYP2C19 and VKORC1 allele frequencies and genotype distribution were derived by gene counting. The VKORC1 haplotypes were statistically inferred by the haplo-stats software, version 1.3 (10), available at http://mayoresearch.mayo.edu/mayo/ research/schaid_lab/software.cfm. This software attributes a posterior probability value to the diplotype configuration for each individual based on estimated haplotype frequencies. Diplotypes were inferred with probabilities $>0.98$, for all individuals.

\section{Statistical analysis}

Deviations from Hardy-Weinberg equilibrium were accessed by the goodness-of-fit chi-square test. Allele and genotype frequencies were compared using the chi-square test or, when appropriate, the Fisher exact test. Statistical significance was set at $\mathrm{P}<0.05$.

\section{Results}

The GSTM ${ }^{*} A{ }^{*} B$ polymorphism was monomorphic in native $(N=89)$ and in first-generation Japanese $(N=64)$ living in Brazil's South region, the variant ${ }^{*} B$ allele not being detected in either group. CYP2C9*2 and ${ }^{*} 3$ were absent or infrequent in these two groups, whereas CYP2C19*3 and, especially, CYP2C19*2 were common in both Japanese groups (Table 1). The genotype frequencies of the CYP2C9 and CYP2C19 polymorphisms did not deviate from expected Hardy-Weinberg proportions. No significant difference was detected between native Japanese and first-generation Japanese born in Brazil with respect to allele frequencies or genotype distribution of the CYP2C9 and CYP2C19 polymorphisms. In contrast, highly significant $(P<0.0001)$ differences in allele frequencies and genotype distribution of the CYP2C9 and CYP2C19 polymorphisms were observed between native Japanese or first-generation Japanese and Brazilians with no Japanese ancestry. These differences resulted from the higher frequency of the CYP2C ${ }^{*} 2$ and *3 alleles, and the lower frequency of the CYP2C19*2 and *3 alleles in Brazilians with no Japanese ancestry compared to native Japanese or first-generation Japanese (Table 1).

Individuals from Japanese communities in the North and South regions of Brazil were genotyped for the VKORC1 polymorphisms. There were no differences in allele of genotype frequencies between the two groups, and the combined data for the two regions are shown in Tables 2 and 3. Native and first-generation Japanese did not differ from each other with respect to the prevalence of the VKORC1

Table 2. Allele frequencies and genotype distribution of VKORC1 polymorphisms in native Japanese, Brazilian-born firstgeneration Japanese and non-Japanese Brazilians.

\begin{tabular}{|c|c|c|c|c|c|}
\hline Single nuc & olymorphisms & Native Japanese $^{a}$ & First-generation ${ }^{a}$ & Non-Japanese Brazilians ${ }^{b}$ & P \\
\hline $3673 G>A$ & GG & $1(0.5 \%)$ & $3(2.4 \%)$ & $170(43.5 \%)$ & \\
\hline & GA & $37(18.5 \%)$ & $24(19 \%)$ & $180(46.2 \%)$ & $<0.0001^{c}$ \\
\hline & AA & $162(81.0 \%)$ & $99(78.6 \%)$ & $40(10.3 \%)$ & \\
\hline & G & $39(9.7 \%)$ & $30(11.9 \%)$ & $520(66.7 \%)$ & $<00001 d$ \\
\hline & A & $361(90.3 \%)$ & $222(88.1 \%)$ & $260(33.3 \%)$ & -0.0001 \\
\hline $5808 T>G$ & TT & $198(99.0 \%)$ & $125(99.2 \%)$ & $243(62.3 \%)$ & \\
\hline & TG & $2(1.0 \%)$ & $1(0.8 \%)$ & $129(33.1 \%)$ & $<0.0001^{c}$ \\
\hline & GG & 0 & 0 & $18(4.6 \%)$ & \\
\hline & $T$ & $398(99.5 \%)$ & $251(99.6 \%)$ & $615(78.8 \%)$ & $<0 \cap 0001$ d \\
\hline & G & $2(0.5 \%)$ & $1(0.4 \%)$ & $165(21.2 \%)$ & $<0.0001^{4}$ \\
\hline $6853 G>C$ & GG & $1(0.5 \%)$ & $3(2.4 \%)$ & $137(35.1 \%)$ & \\
\hline & GC & $35(17.5 \%)$ & $23(18.2 \%)$ & $198(50.8 \%)$ & $<0.0001^{c}$ \\
\hline & $\mathrm{CC}$ & $164(82 \%)$ & $100(79.4 \%)$ & $55(14.1 \%)$ & \\
\hline & $\mathrm{G}$ & $37(9.2 \%)$ & $29(11.5 \%)$ & $472(60.5 \%)$ & $<00001 d$ \\
\hline & C & $363(90.8 \%)$ & $223(88.5 \%)$ & 308 (39.5\%) & \\
\hline $9041 \mathrm{G}>\mathrm{A}$ & GG & $161(80.5 \%)$ & $99(78.6 \%)$ & $146(37.4 \%)$ & \\
\hline & GA & 38 (19\%) & $24(19 \%)$ & 194 (49.7\%) & $<0.0001^{c}$ \\
\hline & $\mathrm{AA}$ & $1(0.5 \%)$ & $3(2.4 \%)$ & $50(12.8 \%)$ & \\
\hline & G & $360(90 \%)$ & $222(88.1 \%)$ & $486(62.3 \%)$ & $<00001^{d}$ \\
\hline & A & $40(10 \%)$ & $30(11.9 \%)$ & $294(37.7 \%)$ & $<0.0001^{4}$ \\
\hline
\end{tabular}

Data are reported as number with percent in parentheses. apooled data for the North and South regions. bata from Ref. 6. ${ }^{\circ}$ Chi-square test or, when appropriate, Fisher exact test for comparisons of genotype distribution across the three groups. ${ }^{\mathrm{d} C h i-s q u a r e}$ test or, when appropriate, Fisher exact test for comparisons of allele frequencies across the three groups. 
Table 3. Haplotype distribution of VKORC1 polymorphisms in native Japanese, Brazilian-born first-generation Japanese and non-Japanese Brazilians.

\begin{tabular}{lccc}
\hline Haplotypes & $\begin{array}{c}\text { Native Japanese } \\
(\mathrm{N}=400)\end{array}$ & $\begin{array}{c}\text { First-generation } \\
(\mathrm{N}=252)\end{array}$ & $\begin{array}{c}\text { Non-Japanese } \\
\text { Braziliana }^{\mathrm{N}}(\mathrm{N}=778)\end{array}$ \\
\hline ATCG & $359(89.8 \%)$ & $220(87.3 \%)$ & $94(12.1 \%)$ \\
GTGA & $35(8.8 \%)$ & $27(10.7 \%)$ & $293(37.6 \%)$ \\
GTCA & $2(0.5 \%)$ & $2(0.8 \%)$ & 0 \\
ATCA & $2(0.5 \%)$ & 0 & 0 \\
GGGA & $1(0.2 \%)$ & 0 & 0 \\
GGGG & $1(0.2 \%)$ & 0 & 0 \\
AGCG & 0 & $1(0.4 \%)$ & $165(21.2 \%)$ \\
ATGA & 0 & $1(0.4 \%)$ & 0 \\
GTGG & 0 & $1(0.4 \%)$ & $178(22.9 \%)$ \\
GTCG & 0 & 0 & $48(6.2 \%)$ \\
\hline
\end{tabular}

Data are reported as number with percent in parentheses. aData from Ref. 6.

polymorphisms examined (Table 2). However, comparison of either group with Brazilians with no Japanese ancestry (Table 2) revealed highly significant differences in both allele frequencies and genotype distribution of each VKORC1 polymorphism. Thus, the variant alleles 3673A and 6853C were two to three times more frequent, and the 9041Aallele was three times less common in the two Japanese groups compared to Brazilians with no Japanese ancestry. The VKORC1 $5808 \mathrm{G}$ allele was rare in the Japanese groups $(0.4 \%)$, whereas it occurred in $21 \%$ of Brazilians with no Japanese ancestry (Table 2).

Table 3 shows the VKORC1 haplotype distribution in the study cohort. Haplotype ATCG was by far the most common (87-90\%) in both native and first-generation Japanese, followed by haplotype GTGA (8-11\%). The other haplotypes accounted for $<2 \%$ total genetic variability in these groups. This haplotype distribution differs markedly from that previously reported for Brazilians with no Japanese ancestry (6), in whom GTGA was the predominant haplotype (38\%), followed by haplotypes GTGG (23\%) and AGCG (21\%). Not surprisingly, a highly significant difference $(P<0.0001$, Fisher exact test) in VKORC1 haplotype distribution was observed between Brazilians with no Japanese ancestry and either native or first-generation Japanese.

\section{Discussion}

The present results indicate that the frequency of genetic polymorphisms in four proteins involved in phases I (CYP2C9 and CYP2C19) and II (GSTM3) of drug metabolism and in drug pharmacodynamics (VKORC1) does not differ between native Japanese and Brazilian-born Japanese descendants living in Brazil. These results are consistent with historical evidence that intermarriage between native
Japanese who had emigrated to Brazil and Brazilians with no Japanese ancestry is unusual (3). Our data for both Brazilian-born, first-generation Japanese and (not surprisingly) for native Japanese living in Brazil are in excellent agreement with published data on individuals born and living in Japan regarding the frequency of polymorphisms in CYP2C9 $(4,11)$, CYP2C19 $(4,11)$ and $\operatorname{VKORC1}(5,12)$. To the best of our knowledge, there are no published data on the frequency of the GSTM3 ${ }^{*} A /{ }^{*} B$ polymorphism in Japanese. If so, our study is the first report of the absence of the GSTM3 ${ }^{*} B$ allele in native Japanese, consistent with results for other Asian populations $(13,14)$.

The striking similarity in the frequency of clinically relevant pharmacogenetic polymorphisms between Brazilian-born Japanese descendants and native Japanese observed in the present study suggests that the former may be recruited for clinical trials designed to generate bridging data for the Japanese population in the context of the $\mathrm{ICH}(1)$. This possibility is all the more attractive in view of the expressive number ( 1.5 million) of Brazilian-born individuals of Japanese ancestry (2). However, it should be acknowledged that the data obtained in the present study cohort, composed of first-generation Japanese descendants living in agricultural colonies, may not be extrapolated to the second- and third-generations of Brazilian-born subjects of Japanese ancestry, especially those individuals living in urban centers, because of the increasing impact of genetic admixture (3). Accordingly, the remarkable differences in the frequency of the studied pharmacogenetic polymorphisms between Brazilians with no Japanese ancestry and either native or first-generation Japanese are likely to be attenuated as the extent of admixture increases.

Among the genes investigated in the present study, CYP2C9 and CYP2C19 encode enzymes that are responsible for the hepatic metabolism of $20 \%$ of all prescribed drugs (15). The CYP2C9*2, CYP2C9*3, CYP2C19*2, and CYP2C19*3 variant alleles are associated with reduced or null enzyme catalytic activity, which may affect drug disposition leading to an altered clinical response. For example, the intrinsic clearance of S-warfarin is reduced in carriers of $C Y P 2 C 9^{*} 2$ and/or $C Y P 2 C 9 * 3$, who require lower warfarin maintenance doses to attain adequate anticoagulation $(16,17)$. Genetic variation in CYP2C19 has been found to modulate the efficacy of proton pump inhibitors such as omeprazole and lansoprazole: data from Japanese cohorts show that carriers of the CYP2C19*2 or *3 variant alleles display higher cure rates for gastroesophageal reflux disease and Helicobacter pylori infection by proton pump inhibitor-based therapies than patients with the CYP2C19*1/*1 genotype (18). The relatively high combined frequency of CYP2C19*2 and *3 in Japanese individuals (confirmed in the present study) may account for these results, which have not been consistently repro- 
duced in other populations $(19,20)$.

The GSTM ${ }^{*} A{ }^{*} B$ polymorphism, a 3-bp insertion/deletion in intron 6 , which may affect regulation and ultimately the amount and activity of GSTM3 (9), has been investigated as a risk factor for cancer, with contradictory results (21-23). The GSTM3 ${ }^{*} A /{ }^{*} B$ polymorphism was monomorphic in our study population suggesting that the increased risk associated with the variant GSTM ${ }^{*} B$ allele may not be relevant to the Japanese and other southeast Asian populations, in which this allele is absent or rare (14).

The VKORC1 polymorphisms examined in the present study are major determinants of warfarin dose requirements in most populations, including the Japanese $(5,12,24)$.

\section{References}

1. Myrand SP, Sekiguchi K, Man MZ, Lin X, Tzeng RY, Teng $\mathrm{CH}$, et al. Pharmacokinetics/genotype associations for major cytochrome P450 enzymes in native and first- and thirdgeneration Japanese populations: comparison with Korean, Chinese, and Caucasian populations. Clin Pharmacol Ther 2008; 84: 347-361.

2. Ministry of Foreign Affairs Japan. http://www.mofa.go.jp/ region/latin/brazil/index.html. Accessed May 10, 2009.

3. Enciclopédia das Línguas no Brasil. http://www.labeurb. unicamp.br/elb/asiaticas/japones.htm. Accessed May 10, 2009.

4. Rosemary J, Adithan C. The pharmacogenetics of CYP2C9 and CYP2C19: ethnic variation and clinical significance. Curr Clin Pharmacol 2007; 2: 93-109.

5. Obayashi K, Nakamura K, Kawana J, Ogata H, Hanada $\mathrm{K}$, Kurabayashi $\mathrm{M}$, et al. VKORC1 gene variations are the major contributors of variation in warfarin dose in Japanese patients. Clin Pharmacol Ther 2006; 80: 169-178.

6. Vianna-Jorge R, Perini JA, Rondinelli E, Suarez-Kurtz G. CYP2C9 genotypes and the pharmacokinetics of tenoxicam in Brazilians. Clin Pharmacol Ther 2004; 76: 18-26.

7. Suarez-Kurtz G, Vargens DD, Struchiner CJ, Bastos-Rodrigues L, Pena SD. Self-reported skin color, genomic ancestry and the distribution of GST polymorphisms. Pharmacogenet Genomics 2007; 17: 765-771.

8. Perini JA, Struchiner CJ, Silva-Assuncao E, Santana IS, Rangel F, Ojopi EB, et al. Pharmacogenetics of warfarin: development of a dosing algorithm for Brazilian patients. Clin Pharmacol Ther 2008; 84: 722-728.

9. Inskip A, Elexperu-Camiruaga J, Buxton N, Dias PS, Maclntosh J, Campbell D, et al. Identification of polymorphism at the glutathione S-transferase, GSTM3 locus: evidence for linkage with GSTM1*A. Biochem J 1995; 312 (Part 3): 713716.

10. Schaid DJ, Rowland CM, Tines DE, Jacobson RM, Poland GA. Score tests for association between traits and haplotypes when linkage phase is ambiguous. Am J Hum Genet 2002; 70: 425-434.

11. Xie HG, Prasad HC, Kim RB, Stein CM. CYP2C9 allelic variants: ethnic distribution and functional significance. Adv Drug Deliv Rev 2002; 54: 1257-1270.

12. Takahashi H, Wilkinson GR, Nutescu EA, Morita T, Ritchie
The VKORC1 gene encodes vitamin K epoxide reductase, which is the target for the anticoagulant effect of warfarin (25). Haplotypes including VKORC1 3673A, which largely predominate among Japanese and other eastern Asian populations (24), predict high sensitivity to the anticoagulant effect of warfarin. This is thought to account for the low-dose phenotype that predominates in these populations, and in view of the present results, may be anticipated to prevail among first-generation, Brazilian-born Japanese.

\section{Acknowledgments}

Research supported by CNPq and FAPERJ.
MD, Scordo MG, et al. Different contributions of polymorphisms in VKORC1 and CYP2C9 to intra- and inter-population differences in maintenance dose of warfarin in Japanese, Caucasians and African-Americans. Pharmacogenet Genomics 2006; 16: 101-110.

13. Cortessis V, Siegmund K, Chen Q, Zhou N, Diep A, Frankl H, et al. A case-control study of microsomal epoxide hydrolase, smoking, meat consumption, glutathione S-transferase M3, and risk of colorectal adenomas. Cancer Res 2001; 61: 2381-2385

14. Tetlow N, Robinson A, Mantle T, Board P. Polymorphism of human mu class glutathione transferases. Pharmacogenetics 2004; 14: 359-368.

15. Evans WE, Relling MV. Pharmacogenomics: translating functional genomics into rational therapeutics. Science 1999; 286: 487-491.

16. Mushiroda T, Ohnishi $Y$, Saito S, Takahashi A, Kikuchi $Y$, Saito S, et al. Association of VKORC1 and CYP2C9 polymorphisms with warfarin dose requirements in Japanese patients. J Hum Genet 2006; 51: 249-253.

17. Lindh JD, Holm L, Andersson ML, Rane A. Influence of CYP2C9 genotype on warfarin dose requirements - a systematic review and meta-analysis. Eur J Clin Pharmacol 2009; 65: 365-375.

18. Furuta T, Sugimoto M, Shirai N, Ishizaki T. CYP2C19 pharmacogenomics associated with therapy of Helicobacter pylori infection and gastro-esophageal reflux diseases with a proton pump inhibitor. Pharmacogenomics 2007; 8: 11991210.

19. van Zanten SV, Thompson K. Should the presence of polymorphisms of CYP2C19 enzymes influence the choice of the proton pump inhibitor for treatment of Helicobacter pylori infection? Am J Gastroenterol 2006; 101: 1476-1478.

20. Padol S, Yuan Y, Thabane M, Padol IT, Hunt RH. The effect of CYP2C19 polymorphisms on $H$. pylori eradication rate in dual and triple first-line PPI therapies: a meta-analysis. Am J Gastroenterol 2006; 101: 1467-1475.

21. De Roos AJ, Gold LS, Wang S, Hartge P, Cerhan JR, Cozen W, et al. Metabolic gene variants and risk of non-Hodgkin's lymphoma. Cancer Epidemiol Biomarkers Prev 2006; 15: 1647-1653.

22. Mcllwain CC, Townsend DM, Tew KD. Glutathione S- 
transferase polymorphisms: cancer incidence and therapy. Oncogene 2006; 25: 1639-1648.

23. Schwartzbaum JA, Ahlbom A, Lonn S, Malmer B, Wigertz A, Auvinen A, et al. An international case-control study of interleukin-4Ralpha, interleukin-13, and cyclooxygenase-2 polymorphisms and glioblastoma risk. Cancer Epidemiol Biomarkers Prev 2007; 16: 2448-2454.
24. Lee SC, Ng SS, Oldenburg J, Chong PY, Rost S, Guo JY, et al. Interethnic variability of warfarin maintenance requirement is explained by VKORC1 genotype in an Asian population. Clin Pharmacol Ther 2006; 79: 197-205.

25. Li T, Chang CY, Jin DY, Lin PJ, Khvorova A, Stafford DW. Identification of the gene for vitamin $\mathrm{K}$ epoxide reductase. Nature 2004; 427: 541-544. 